\title{
Prospects of regenerative current breaking in DC circuit breaker topology
}

\author{
S. M. Sanzad Lumen, Ramani Kannan, Nor Zaihar Yahaya
}

Department of Electrical and Electronics Engineering, Universiti Teknologi PETRONAS, Seri Iskandar, Ipoh, Malaysia

\begin{tabular}{l}
\hline \hline Article Info \\
\hline Article history: \\
Received Dec 17, 2020 \\
Revised Feb 5, 2021 \\
Accepted Apr 4, 2021 \\
\hline
\end{tabular}

\section{Keywords:}

Current breaking

DC circuit breaker

Fault current

Protection

Regeneration

\begin{abstract}
Due to the stunning advancement of power electronics, DC power system is getting immense attention in the field of research. Protection and hereafter the protective devices for the DC power system application are two vital areas that need to be explored and developed further. Designing a protective device such as DC circuit breaker possesses a lot of challenges. The main challenge is to interrupt a current which does not have a natural zero crossing like AC current has. In addition, energy is stored in the network inductances during normal operation. Instantaneous current breaking is opposed by this stored energy during circuit breaker tripping, hence, all the DC circuit breaker topologies proposed in literature use snubber network, nonlinear resistor to dissipate this stored energy as heat during the current breaking operation. However, it is possible to store this energy momentarily and reuse it later by developing an improvised topology. In this paper, the prospects of energy recovery and reuse in a DC circuit breaker was studied and a new topology with regenerative current breaking capability had been proposed. This new topology can feed the stored energy of the network back into the same network after breaking the current and thus can improve the overall system efficiency.
\end{abstract}

This is an open access article under the CC BY-SA license.

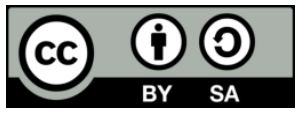

\section{Corresponding Author:}

S. M. Sanzad Lumen

Department of Electrical and Electronics Engineering

Universiti Teknologi PETRONAS

Seri Iskandar, Ipoh, Malaysia

Email: s_18003309@utp.edu.my

\section{INTRODUCTION}

Microgrid concept has emerged as the new norms for electricity distribution recently. As stated in literature that "Microgrids are local energy networks that involve renewable energy sources and storage systems". DC microgrid is a convenient mechanism for integrating distributed energy resources (DERs) and local loads into a fully integrated system. Different types of voltage source converter (VSC) like AC to DC, DC to DC are used as building blocks for the microgrid network. DC micro grids have demonstrated superiority over AC micro grids in terms of reliability, efficiency, control simplicity, integration of renewable energy sources, and connection of DC loads. Nevertheless, DC power system is also getting immense attention in the field of HVDC transmission, electric vehicle, electric traction load. Despite these many advantages, there are significant challenges to design an appropriate protection scheme for DC power system as well. Basically, the challenge stems from the nature of DC fault current, which can rapidly increase to more than a hundred times of the nominal current during sudden fault inception and has no naturally occurring zero crossing point like $\mathrm{AC}$ has. Proper grounding architecture, fast and efficient fault detection strategy, fault current limiting method and an appropriate DC circuit breaker (DCCB) are required 
to address the challenges of DC system protection [1]-[3]. DCCB used for current interruption in a DC network is an integral part of the system. In this paper, different types of DCCB topologies had been discussed to exploit their limitations and a new topology with unique current breaking feature was presented and evaluated. The structure of this paper is as follows: Section 1 gives the brief background of the topic along with literature reviews, related works, and problem statement. Section 2 introduces and discusses the new DCCB topology. Section 3 describes the research methodology in detail with a methodology flow chart and later discusses the mathematical modelling and working principle of the proposed topology thoroughly. Section 4 presents the simulation results, compare the performance with conventional topology and thus validates the proposed concept.

In order to break the current in any network, circuit breakers are used. Circuit breakers usually make a break in the current path by separating mechanical contacts or by solid state turn off process. In mechanical turn off process, as the contacts separate, arc is initiated in between them, and this arc needs to be extinguished quickly to break the current efficiently as well as to keep the contacts undamaged. In AC network due to the sinusoidal nature of the current, natural current zero situation arises twice in a full cycle. Using different arc extinguishing techniques, circuit breaker usually breaks the current at these current zero instances. This process of current breaking is quite straightforward in AC network but in DC network, it is not that simple. Natural current zero is not available in DC network and that makes the breaking of DC current using conventional circuit breaker very challenging [4], [5]. Furthermore, when current flows in a DC network, energy is stored in the inductance of the line as well as in the filter elements of the DC/DC converters. As a result, current in this network cannot be broken instantaneously, otherwise it will create high potential stress on the breaker contacts, create and maintain arc for longer period of time and damage the contacts in the process. Similarly, in case of solid state turn off process, sudden ceasing of current flow in an inductive DC network will develop a high potential stress across the device and may damage it. For safe and efficient breaking of DC current, it must be reduced to zero and the stored energy of the network must be dissipated during the process. Snubber network or impedance network or nonlinear resistor or a combination of them are used in the DCCB to absorb and dissipate the network energy as heat and to assist in the current reduction followed by breaking. As per literature, DC circuit breakers are mainly divided into three categories: 1) Mechanical circuit breakers which are similar to the traditional mechanical switches; 2) Solid-state circuit breakers that perform interruption by power electronic devices and 3) Hybrid circuit breakers that combine both mechanical and solid-state technologies together. Besides, with the development of power electronics, DC solid-state circuit breakers have also been greatly improved and an upgraded version called Z-source solid-state circuit breaker has been proposed [6]-[8].

The basic mechanical circuit breaker (MCB) is composed of a mechanical switch, a commutation circuit, and an energy absorber circuit. The scheme of MCB using passive and active commutation circuits are shown in Figure 1(a). Under normal operating condition, the mechanical switch conducts the load current. Once the breaker receives a trip signal, the mechanical switch opens, and an arc is initiated. The arc voltage forces the current to shift from the load current path to the commutation path. Then the commutation circuit consisting of a capacitor and inductor in series generates a growing current oscillation. While the amplitude of the oscillating commutation current $\left(I_{C}\right)$ becomes sufficiently large, zero-crossing points are created in the mechanical switch current $\left(I_{n}\right)$ and the mechanical switch extinguishes the arc and interrupts the current at the first zero crossing point. A metal oxide varistors (MOV) is used to limit the voltage across the switch. The main advantages of MCBs are low power loss and relatively low cost; however, slow response time and limited current interruption capability are the main disadvantages [9], [10].

Semiconductor based switches are used as the current interrupting element in DC circuit breaker to address the problem of slow time response. A typical solid-state circuit breaker (SSCB) is shown in Figure 1(b). Among the different type of semiconductor switching devices, thyristor, GTO, IGCT and IGBT are mostly used as SSCB. The operation procedure is very simple in SSCB. Except thyristor, all the remaining switches are fully controllable meaning that they can be turned on or turned off easily by control signal. But thyristor requires extra commutation circuit for turn off process and it takes time and this delay leads to high fault current. However, thyristors have the lowest conduction losses and such a low on-state loss results in reduction of overall costs of the SSCB. A MOV is used parallel to the switching device to limit the voltage surge during current interruption. Though SSCB provides faster operation but higher conduction loss and bulky cooling systems are two of its limitations [11]-[14]. 


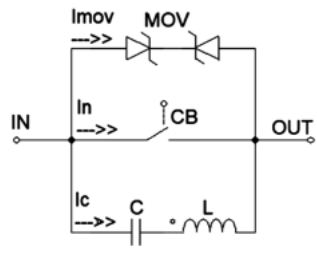

(1)

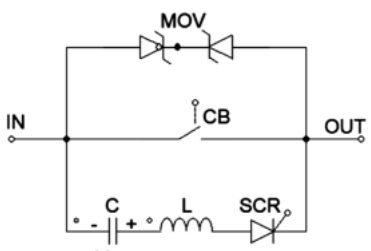

(2)

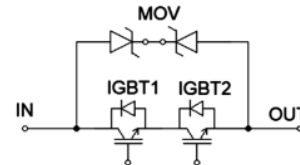

(1)

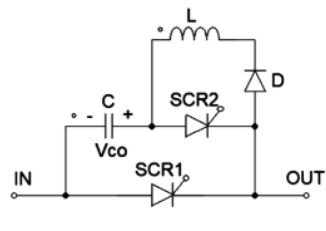

(a)

(b)

Figure 1. Typical DCCB topology; (a) MCB with: (1) Passive commutation circuit,

(2) Active commutation circuit; (b) SSCB based on: (1) IGBT, (2) Thyristor

Hybrid circuit breaker (HCB) is a new class of DCCB that combines both the MCB and the SSCB to take advantages of both. As a result, $\mathrm{HCBs}$ have advantages such as fast response, low power loss and negligible arcing across the mechanical contacts. As shown in Figure 2(a), a conventional HCB has three main parts including a fast-mechanical switch (FMS), a high-voltage solid state (SS) switch as the main breaker (MB), and a MOV. During normal operation, the current passes through FMS. When a trip signal is received, the FMS starts opening and sends a turn-on signal to the MB. Due to the arc voltage, current shifts naturally from the FMS to the MB. Once the FMS gains sufficient breakdown strength, the MB is turned off and the voltage increases rapidly because of circuit inductances. While the voltage reaches breakdown voltage, the MOV turns on to clamp voltage and the fault current now commutes through MOV and decays to zero. Finally, when the current becomes zero, the residual current breaker (RCB) opens to provide complete galvanic isolation. Despite having many advantages, HCB has few challenges as well. Differences in reaction times and current ratings of the FMS branch and MB branch, dependency of mechanical contacts separation on the fault magnitude, requirement for a higher arc voltage are few of the challenges [15]-[17].

Z-Source circuit breaker (ZSCB) is a developed form of the SSCB. The scheme of the original ZSCB is shown in Figure 2(b). While in operation, once the fault occurs, the fault current flows through the capacitors as the current through the inductor cannot change instantaneously. At this point, each of the capacitor current increases to reach the prefault inductor current. When the capacitor current equals the inductor current, the SCR current becomes zero and causes the SCR to turn off. In the next stage, the two series (L-C) branches connected to the fault and load form resonance and hence current oscillation is developed. During this oscillation, the diodes turn on to bypass the current from the capacitor. The capacitors discharge through the resistor and the inductor current also circulates in the inductor/resistor/diode loop until it decays to zero. Although ZSCB has some benefits over MCB and SSCB, it cannot operate for less severe and lower dynamic fault. In addition to that, ZSCB also faces limitations like not having common ground between source and load, undesirable frequency response, high spike current during the reconnection [18], [19].

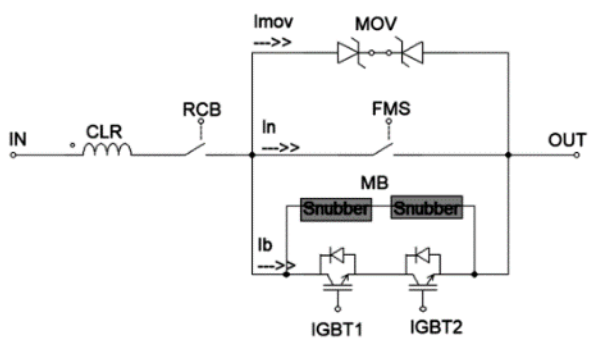

(a)

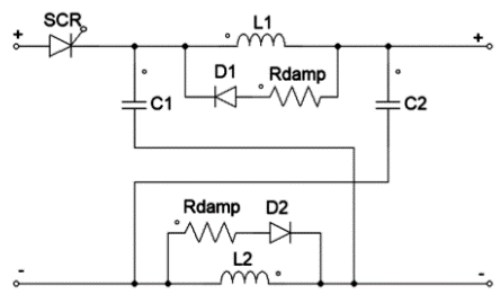

(b)

Figure 2. Typical DCCB topology: (a) Hybrid circuit breaker, (b) Z-source circuit breaker

Apart from the conventional topologies, some modified and updated versions of them are also proposed in literature such as proactive hybrid circuit breaker; hybrid circuit breaker with COMMUTATION booster; superconductor based hybrid circuit breaker; ZSCB based on Coupled Inductors, fast current releasing SSCB topology, coupled-inductor Solid State circuit breaker, gas discharge tube (GDT) based circuit breaker [20], [21]. Table 1 summarizes the advantages and disadvantages of the different topologies.

Prospects of regenerative current breaking in DC circuit breaker topology (S. M. Sanzad Lumen) 
Table 1. An overview of different DC circuit breaker topologies

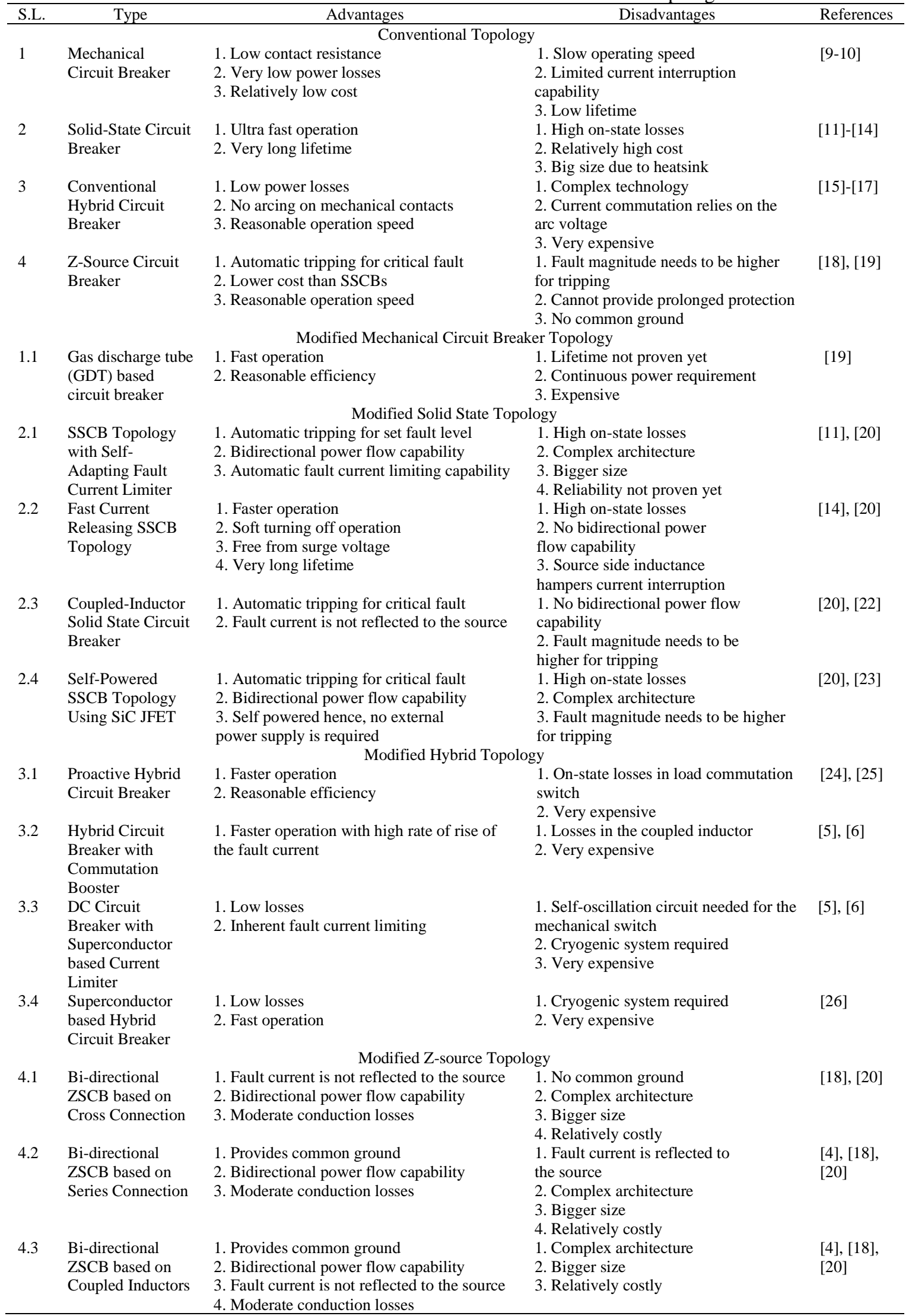


Different types of DCCB topologies have different advantages and limitations. But all the topologies have a common drawback in terms of current breaking technique. Almost all the topologies use either snubber network or impedance network or nonlinear resistor or a combination of them as absorber circuit to dissipate the stored energy of the network as heat during each current breaking operation. This conventional current breaking technique makes the DCCB an inefficient device in the network. Because a significant amount of energy is wasted during every current breaking operation in a high current network. But instead of dissipating, the stored energy can be reused in a similar way like the regenerative braking in electrical drive system works. As we are striving for more energy efficient technology for every day application for a sustainable future, if there is a slightest scope of energy conservation, it should be grasped whole heartedly. However, from the knowledge of literature, there is hardly found any study that deals with energy reuse capability of a DCCB topology. Hence, this paper will explore the scopes and techniques of current breaking with regeneration, will propose a new DCCB topology with energy regeneration capability, will build the mathematical modelling and validate the proposed concept through simulation.

\section{PROPOSED WORK}

Regenerative braking is a well-known technique used in electrical drive system. When a motor runs, mechanical energy is stored in the rotor as rotational kinetic energy. In electrical drive system, when a running motor needs faster deacceleration, the drive system forces the motor to operate as a generator by taking electrical energy from it and feeding this electrical energy back into the source. Thus, the mechanical energy of the rotor is absorbed by the drive system and a negative torque is generated which deaccelerates the motor faster. In addition, the energy absorbed by the drive system is reused to recharge the battery if battery was used as a source or simply used to supply to other loads connected to the source. This technique increases the overall efficiency of the system on a greater scale. Similarly, in a DC network, energy is stored in terms of current in the network inductances and while breaking this current, the energy can be absorbed and fed back to the source afterwards. Brief summary of some related scholarly and patented works is shown in Table 2 which establishes that the concept of regenerative current breaking in circuit breaker [21] is very much novel and the terminology has not been either used in any literature. Though some studies presented topologies which utilize network energy to operate itself and does not require any external power [22], [23]; but those are not dealing with the greater domain of energy regeneration.

Table 2. Summary of related scholarly and patented works

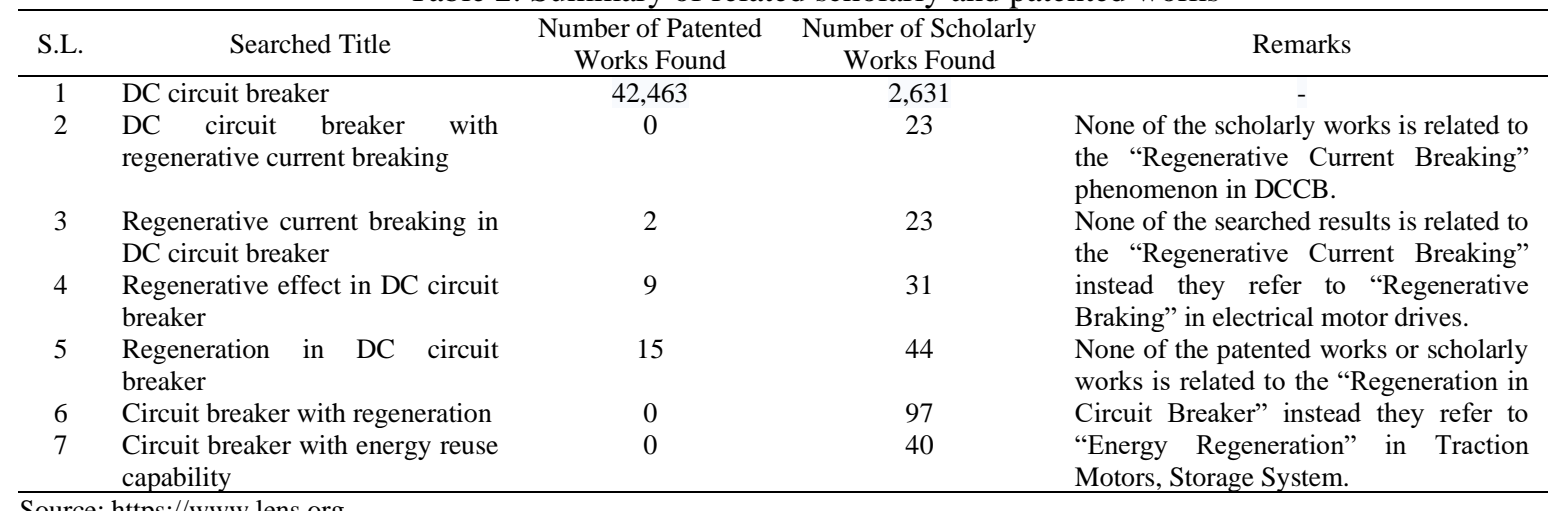

Figure 3 presents the proposed DCCB topology which is consisted of mechanical switches, thyristors, diodes, IGBT, capacitor and inductor. As per the proposed regenerative current breaking concept, upon receiving a trip signal, the source current is diverted from the main branch to the impedance network (L-C network) inside the circuit breaker to reduce the current to zero initially; and to store the energy within the capacitor in terms of voltage. Once the current reduces to zero, the load is isolated from the source side and subsequently the stored energy of the capacitor is fed back into the source side network. This topology is expected to regenerate energy after breaking the current in any DC network. The detail working principle and mathematical modelling are presented in section 3 . 


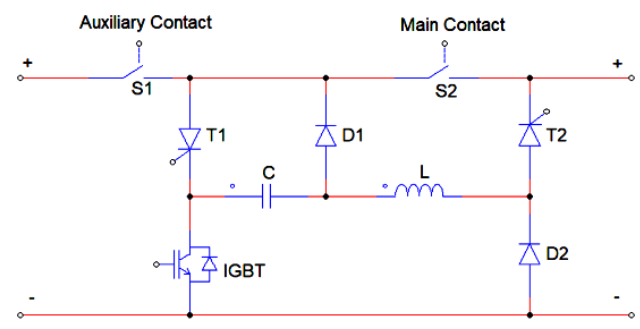

Figure 3. Proposed DCCB topology

\section{RESEARCH METHOD}

This section describes the research methodology, presents the methodology flow chart, and finally discusses the mathematical modelling and working principle of the proposed topology thoroughly.

\subsection{Methodology}

A detail graphical representation of the research methodology is stated in Figure 4 that shows different phases of the research. The research work was conducted through simulation and analysis to meet the following two objectives:

a. To design and model a new DCCB topology with regenerative current breaking capability.

b. To simulate and evaluate the performance of the proposed model.

\section{Phase-1: Literature review and simulation of the existing DCCB models}

The first step of this research was to extensively go through literature on different DCCB topologies, to understand their working principle and to find out their limitations. Special focus was given to their current breaking mechanisms to exploit the drawbacks and to generate new ideas for feasible solution.

\section{Phase-2: Modeling of the proposed regenerative current breaking technique}

The mathematical model of both current breaking and regeneration operation was developed in this phase. Later, a new topology was devised to be best fitted with the mathematical model followed by developing a control algorithm for generating coordinated switching signals for the topology.

\section{Phase-3: Simulation and analysis}

In the final phase, the proposed DCCB was simulated in PSIM software. A radial DC network with source resistance and inductance was used for simulation. The proposed DCCB model was applied in this network to break the current and to regenerate current afterwards. In addition to that, properties such as current breaking time, voltage stress on the breaker, voltage disturbance in the network. were thoroughly investigated and evaluated.

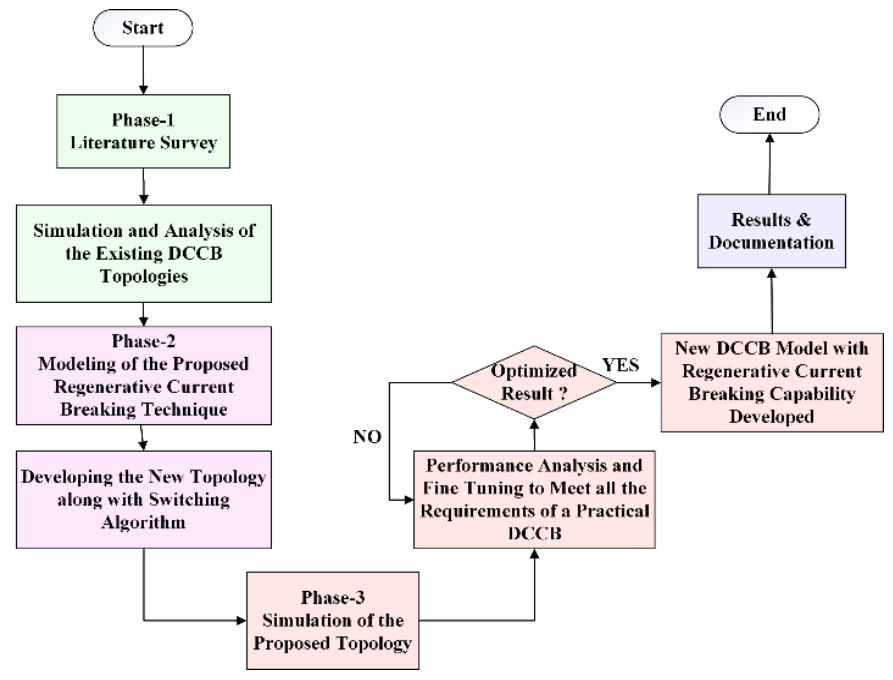

Figure 4. Methodology flow chart 


\subsection{Modeling}

Mathematical modelling of the proposed topology is explained in this subsection. Necessary differential equations based on simple circuital analysis are developed and then solved to find the time domain responses which justifies the working principle.

\subsubsection{Mathematical model for current breaking}

The proposed regenerative current breaking technique was formulated based on the concept that inductor and capacitor form resonant circuit which creates current oscillation when connected to a voltage source and they store energy cyclically in terms of current $(I)$ and voltage $(V)$ respectively. Energy stored in an inductor and capacitor is calculated as $\frac{1}{2} L I^{2}$ and $\frac{1}{2} C V^{2}$ respectively where, $L$ stands for inductance and $C$ for capacitance. As shown in Figure 5(a), when current flows in a DC network, energy is stored in the source inductance $L_{s}$. As soon as the breaker receives a trip signal, the fast-operating mechanical switch (S2) opens, and an arc voltage is initiated. At the same time, gate pulses are sent to the thyristors (T1 \& T2). Due to this combined effect, the load current is commutated from the main branch in to the secondary branch (impedance network) as shown in Figure 5(b). This impedance network consisting of $L$ and $C$ generates a current oscillation at its natural resonant frequency. This current oscillation diverts the main branch current completely and thus the arc voltage cannot go very high and the arc is extinguished very quickly. The current oscillation is governed by (1). It is to be noted that the source current and load current are synonymous here.

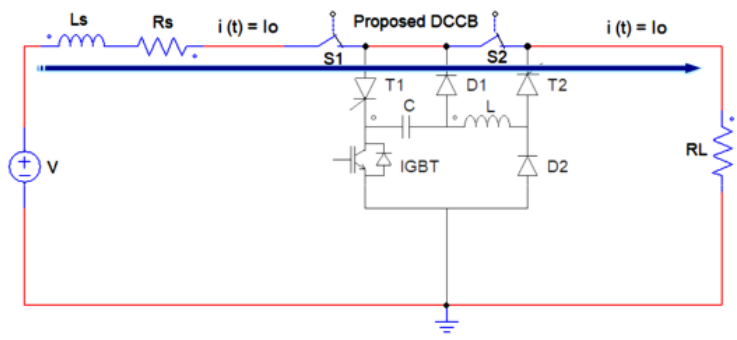

(a)

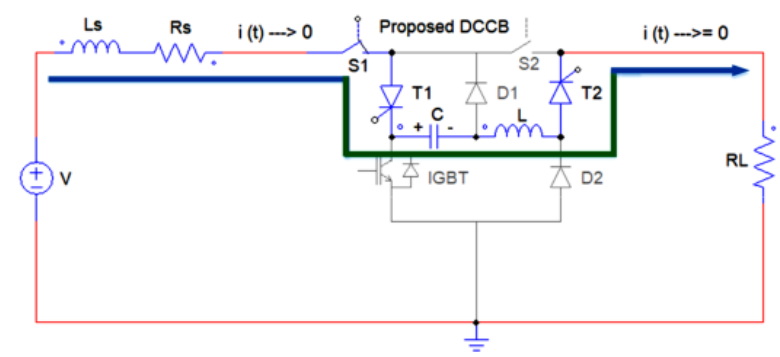

(b)

Figure 5. Current breaking operation in the proposed circuit breaker: (a) Source current path before tripping initiated, (b) Source current path after tripping initiated

$$
\left(L_{s}+L\right) \frac{d i(t)}{d t}+\left(R_{s}+R_{L}\right) i(t)+\frac{1}{C} \int i(t) d t=V, i(t=0)=I_{0}
$$

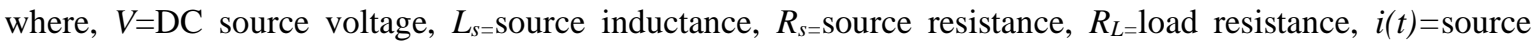
current, $I_{o=}$ initial value of source current, $L=$ breaker inductance, $C=$ breaker capacitance. The solution of (1) is given by (2) where, $\alpha=\frac{\left(R_{S}+R_{L}\right)}{2\left(L_{S}+L\right)}$ is the damping factor, $\omega_{r}=\frac{1}{\sqrt{\left(L_{S}+L\right) C}}$ is the resonance frequency, $\beta=$ $\sqrt{\alpha^{2}-\omega_{r}^{2}}, A=I_{0}$ and $B=\frac{V+I_{0}\left(\alpha L-R_{S}\right)}{\beta L}$.

$$
i(t)=e^{-\alpha t}(A \cos \beta t+B \sin \beta t)
$$

In (2) is a damped oscillation which decays to zero ultimately as shown in Figure 6(a). However, during the first zero-crossing point of this oscillating current, the thyristors $\left(\mathrm{T}_{1}\right.$ and $\left.\mathrm{T} 2\right)$ are turned off by natural commutation and the capacitor $C$ remains charged as shown in Figure 6(b). As the thyristors are now turned off, the load becomes totally disconnected from the source completing the current breaking operation successfully. 

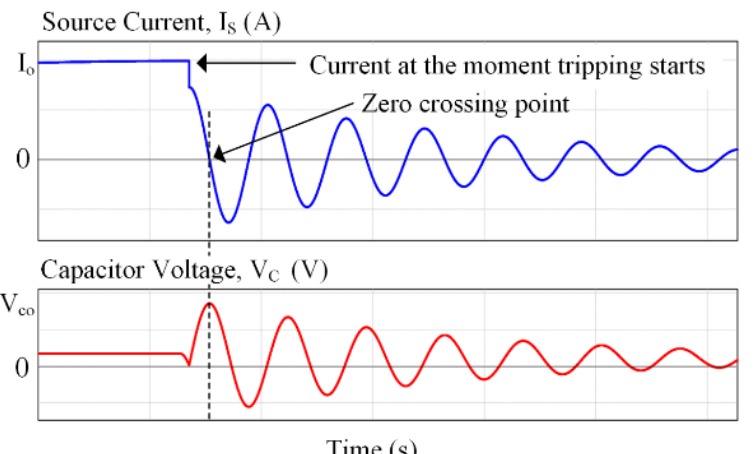

(a)
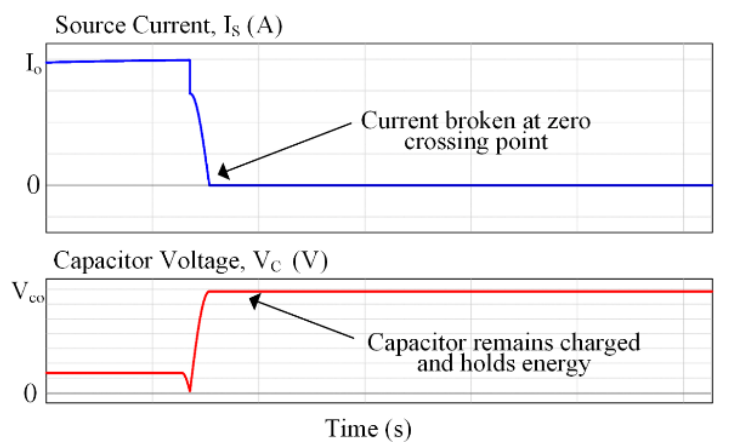

(b)

Figure 6. Dynamic responses during current breaking operation: (a) Current and voltage oscillation as per (2), (b) Current breaking and capacitor charging

\subsubsection{Mathematical model for regeneration}

Once the thyristors are turned off, the IGBT turns on and the capacitor $C$ discharges through the inductor $L$, and thus stored energy of the capacitor is transferred to the inductor as shown in Figure 7(a). The current response is governed by (3) whose solution is (4) where, $V_{c o}=$ initial capacitor voltage, $i_{r}(t)=$ regenerated current and $\omega_{r}{ }^{\prime}=\frac{1}{\sqrt{L C}}$ is the resonance frequency.

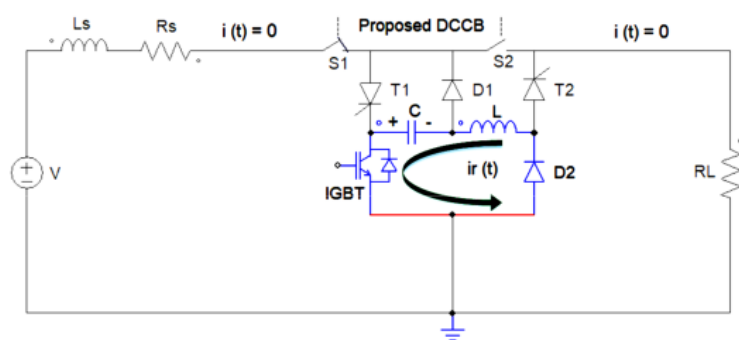

(a)

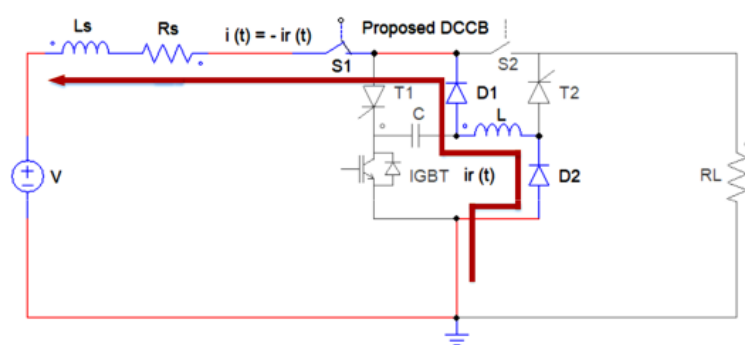

(b)

Figure 7. Regeneration operation in the proposed circuit breaker: (a) Capacitor transfers energy to the inductor, (b) Inductor releases energy in to the source side network

$$
\begin{aligned}
& L \frac{d i_{r}(t)}{d t}+\frac{1}{C} \int i_{r}(t) d t=0, i_{r}(t=0)=0, V_{C}(t=0)=V_{c o} \\
& \left.i_{r}(t)=V_{c o} \sqrt{\frac{c}{L}} \sin \omega_{r}^{\prime} t\right)
\end{aligned}
$$

In (4) is a simple sinusoidal response which cyclically transfers energy back and forth in between L and $\mathrm{C}$ as can be seen in Figure 8(a). But as soon as the capacitor is completely discharged in this oscillation, the control system turns off the IGBT forcing the inductor current to flow through diodes (D1 \& D2) and thus energy from inductor is released into the source side network. This phenomenon of releasing energy back into the source side network is defined as regeneration and is shown in Figure 8(b). The equation for the regenerated current and its time domain response are given by (5) and (6) respectively.

$$
\begin{aligned}
& \left(L_{s}+L\right) \frac{d i_{r}(t)}{d t}+R_{S} i_{r}(t)=V, i_{r}(t=0)=-I_{r 0} \\
& i_{r}(t)=-I_{r 0} e^{-\frac{R_{S}}{L_{S}+L} t}+\frac{V}{R_{S}}\left(1-e^{-\frac{R_{S}}{L_{S}+L} t}\right)
\end{aligned}
$$


where, $\mathrm{Vco}=$ initial capacitor voltage, Iro=initial inductor current. The regenerated current ir(t) from inductor $\mathrm{L}$ has a peak value of Iro that exponentially reduces to zero while being fed back. Once the regenerated current reduces to zero, the auxiliary switch (S1) turns off and the breaker resets for next operation.

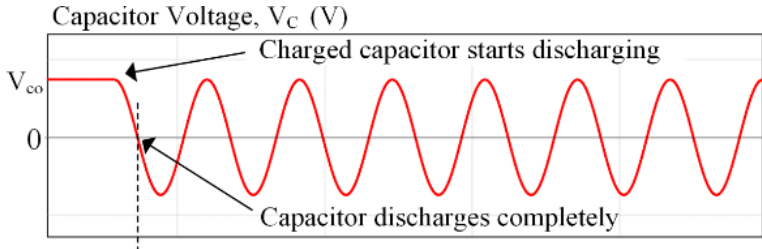

Capacitor Current, $\mathrm{I}_{\mathrm{C}}(\mathrm{A})$ / Inductor Current, $\mathrm{I}_{\mathrm{L}}(\mathrm{A})$

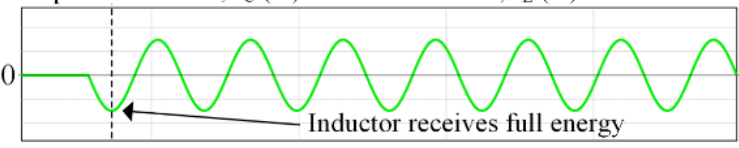

Time (s)

(a)

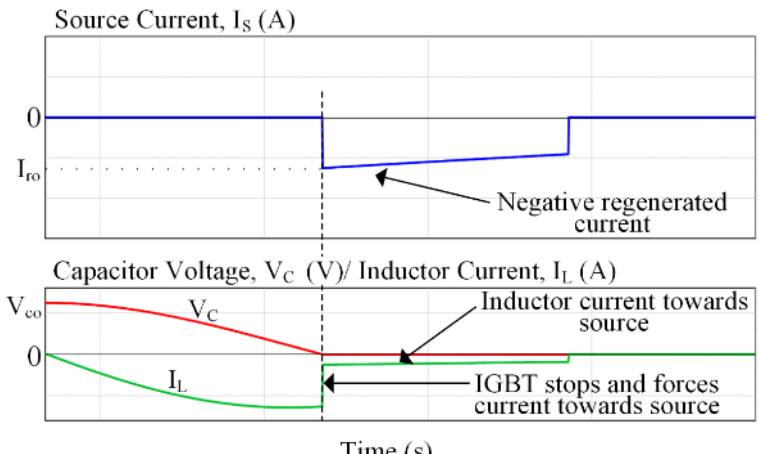

(b)

Figure 8. Dynamic responses during regeneration: (a) Current and voltage oscillation as per (4), (b)

Regenerated current as per (6)

\section{RESULTS AND DISCUSSION}

This section discusses the results of the simulation studies and thus validates the proposed concept. The proposed DCCB topology was modeled and simulated in PSIM software. Both current breaking and regenerative action of the proposed topology were studied and validated.

\subsection{Simulation}

For simplicity, a simple radial DC network as shown in Figure 9 was simulated taking the following simulation parameters: $V_{D C}=400 \mathrm{~V}, L_{S}=200 \mathrm{mH}, R_{S}=0.1 \Omega, R_{L}=0.9 \Omega, L=50 \mathrm{mH}$, and $C=2000 \mu \mathrm{F}$. The simulation was run for 2 second and satisfactory results as discussed in the following subsections were found.

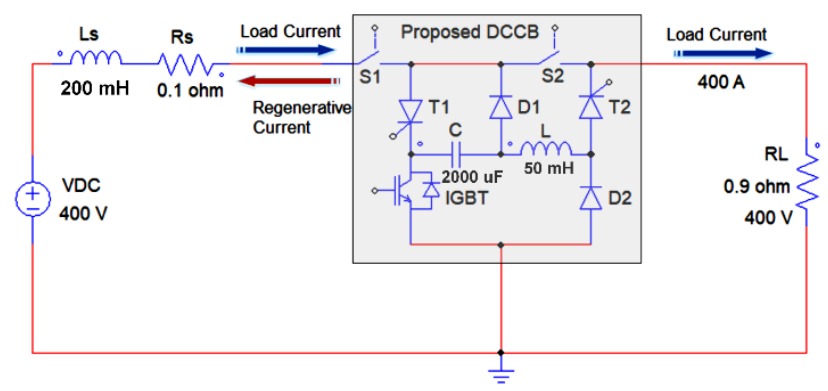

Figure 9. Simulated DC network

\subsubsection{Current breaking}

The current commutation, reduction and voltage across main contact are shown in Figure 10(a) which shows that the DCCB turns on at time, $t=0.055 \mathrm{~s}$ upon receiving a closing pulse and the source current rises and reaches to $400 \mathrm{~A}$. At time, $\mathrm{t}=1.5 \mathrm{~s}$, the circuit breaker receives a trip signal and the tripping starts. At the initiation of tripping, the main contact open, and the thyristors turn on forcing the source current to shift into the impedance network as can be seen in Figure 10(a). The impedance network forms resonance and due to the resonance effect, the current zero point is created, and the thyristors turn off at this point isolating the load from the source side. Figure 10(b) shows the current and voltage responses in the impedance network. As the current zero point is reached and thyristors turn off, the capacitor remains charged until it discharges during regeneration. The current breaking time found in the simulation was recorded as $51.6 \mathrm{~ms}$. 


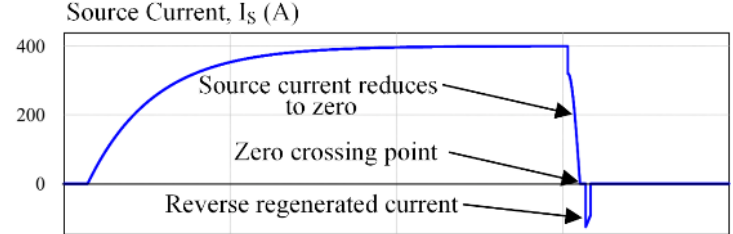

Voltage Across Main Contact, $\mathrm{V}_{\mathrm{S} 2}(\mathrm{~V})$
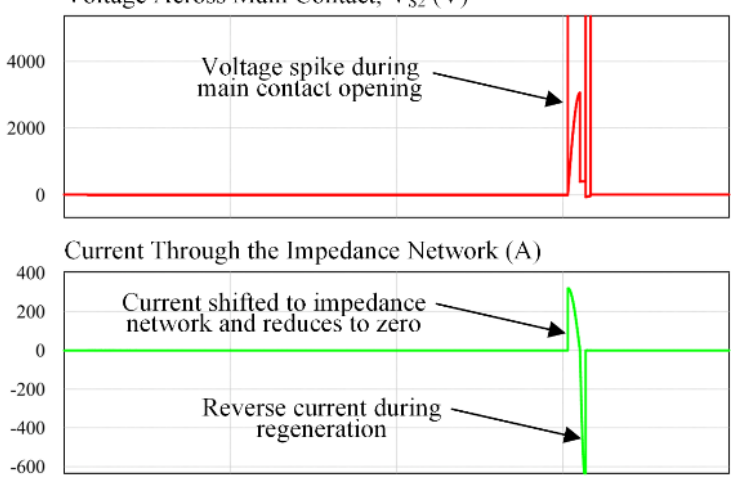

CB Closing and Tripping Pulse (V)

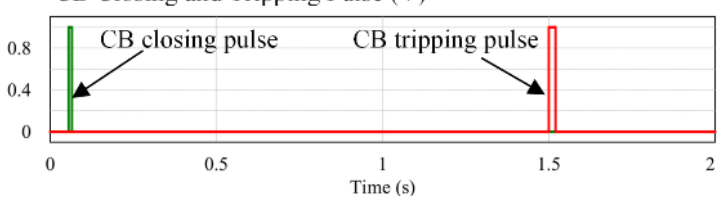

(a)
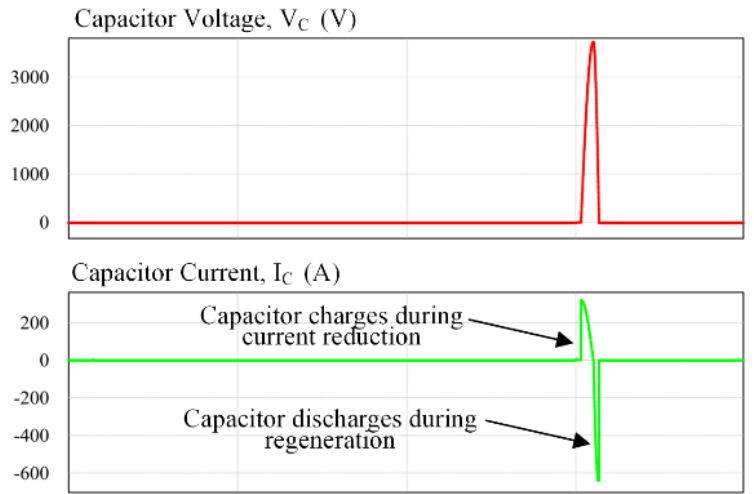

Inductor Current, $\mathrm{I}_{\mathrm{L}}$ (A)
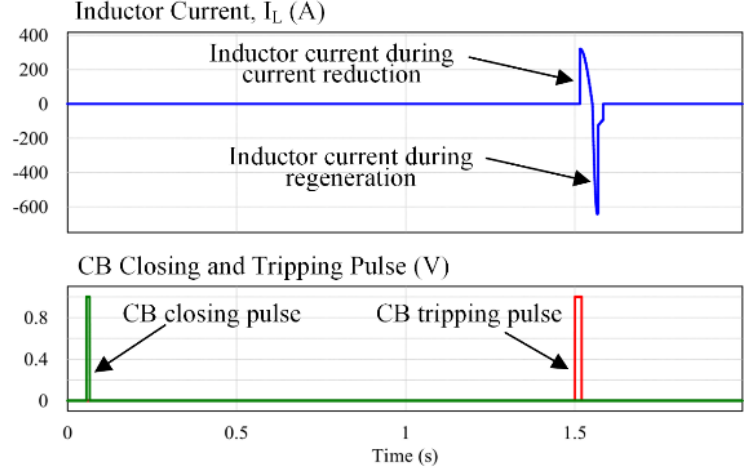

(b)

Figure 10. Currents and voltages in the main branch and impedance network during circuit breaker operation:

(a) Current commutation and switch voltage, (b) Current and voltage in the impedance network

\subsubsection{Regeneration}

When the source current reduces to zero, the DCCB becomes ready for regeneration sequence. The IGBT turns on at time, $\mathrm{t}=1.57 \mathrm{~s}$ and the charged capacitor starts discharging to the inductor. Energy is transferred from the capacitor to the inductor. As soon as the capacitor discharges completely and capacitor voltage becomes zero, the IGBT turns off forcing the inductor to conduct through diodes. As a result, the inductor releases the energy into the source side network and regeneration takes place. The inductor current which later becomes regenerated current is shown in Figure 10(b). A simple control algorithm generates the coordinated switching signals for the switching devices. The control and switching signals are shown in Figure 11(a). The mechanical switches turn on upon receiving a closing pulse. Switch (S2) turns off and thyristors turn on upon receiving a tripping pulse. Then the IGBT turns on to initiate regeneration. The regenerated current and power along with source voltage are shown in Figure 11(b). It is found that $111 \mathrm{~A}$ of average current with a peak value of $125 \mathrm{~A}$ and around $78 \mathrm{MW}$ of average power with a peak value of 312 MW have been regenerated from the breaking of 400 A current. The energy density during regeneration is very high since the regeneration time period is very small, $0.15 \mathrm{~ms}$ only. The amount of regenerated energy is calculated as $11.87 \mathrm{~kJ}$. The summary of the simulation result is shown in Table 3.

Table 3. Simulation results

\begin{tabular}{lll}
\hline S.L. & Criteria & Achievement \\
\hline 1 & Current Breaking Time (Ttrip) & $51.6 \mathrm{~ms}$ \\
2 & Regenerated Current (IR) & $111 \mathrm{~A}$ (Average) \\
3 & Regenerated Power (PR) & $78 \mathrm{MW}$ (Average) \\
4 & Regenerated Energy (ER) & $11.87 \mathrm{~kJ}$ \\
5 & Energy Recovery Efficiency (n) & $35.4 \%$ \\
\hline
\end{tabular}




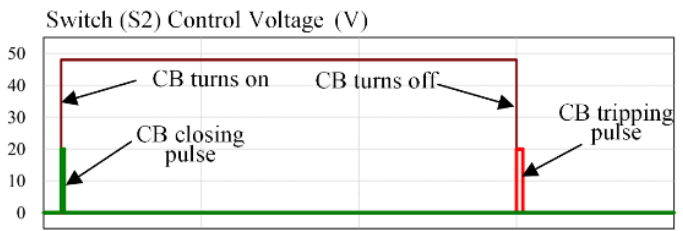

Switch (S1) Control Voltage (V)

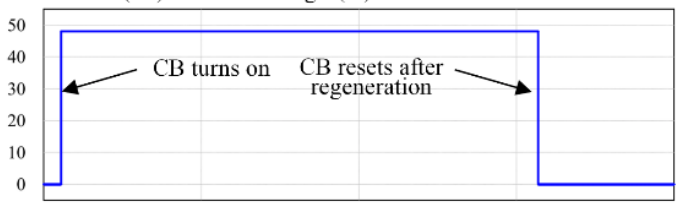

Thyristor Gate Pulse, $\mathrm{V}_{\mathrm{gT}}(\mathrm{V})$

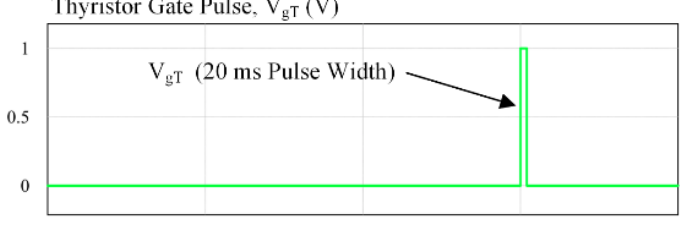

IGBT Gate Control, $\mathrm{V}_{\mathrm{gI}}(\mathrm{V})$

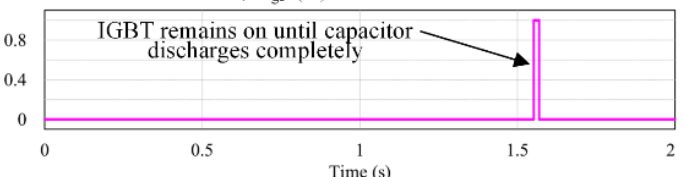

(a)
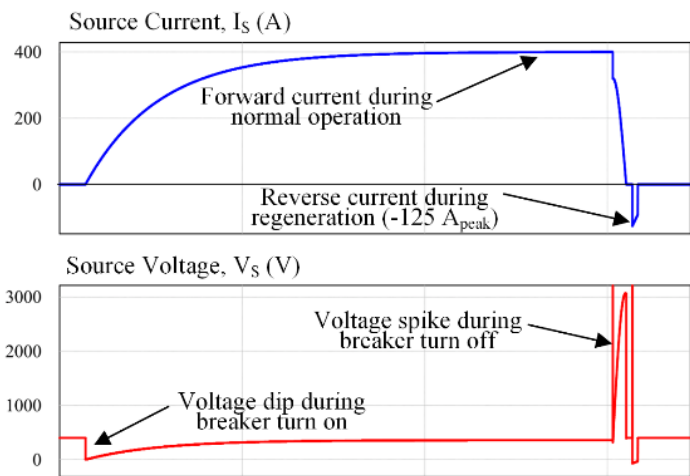

Source Power, $\mathrm{P}_{\mathrm{S}}(\mathrm{W})$

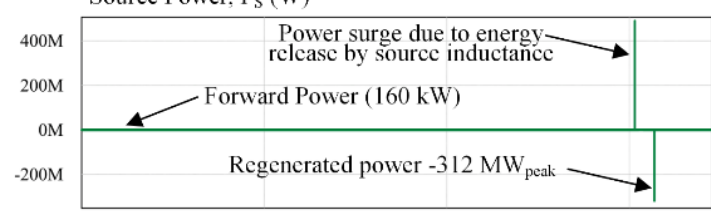

CB Closing and Tripping Pulse (V)

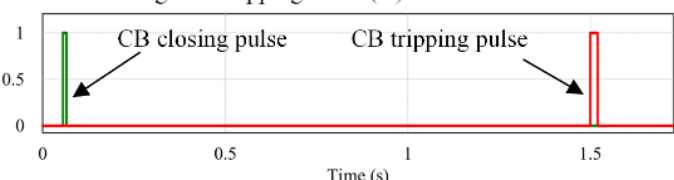

(b)

Figure 11. Control signals and current voltage responses of the source side network: (a) Control signals and switching signals, (b) Source current, voltage, and power during simulation

\subsection{Performance evaluation}

The transient responses during current breaking of a conventional topology and the proposed topology are shown in Figure 12 where the distinctions are clearly visible. Though the tripping time for both the topologies are almost equal but the main novelty of the proposed topology is its regeneration capability. Conventional topology dissipates energy in the absorber circuit as shown in Figure 12(a) while the proposed topology regenerates it as can be seen in Figure 12(b). This regeneration effect is claimed to be the novel feature of the proposed topology.

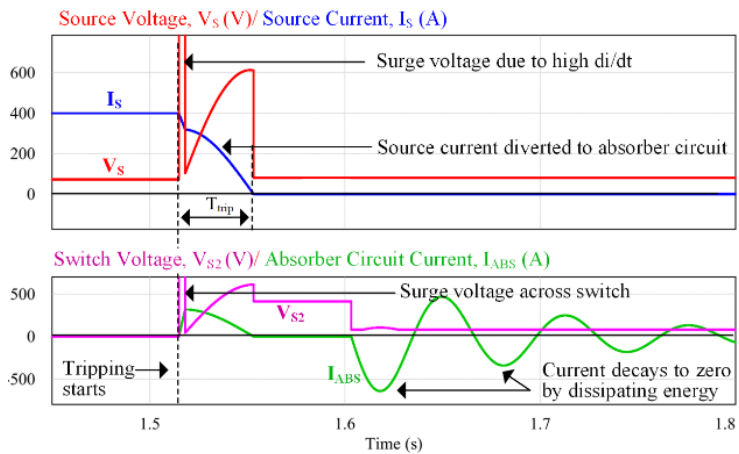

(a)

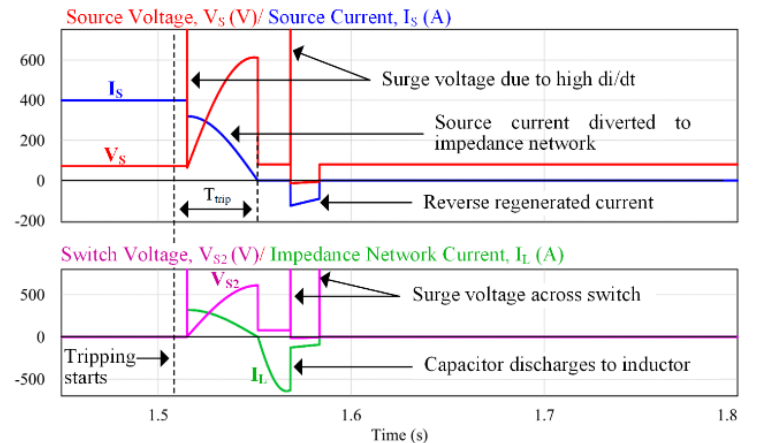

(b)

Figure 12. Transient responses during current breaking in conventional and proposed topology (All the voltages have been scaled down to $1 / 5^{\text {th }}$ of the actual value): (a) Current breaking in a conventional topology,

(b) Current breaking in the proposed topology

\section{CONCLUSION}

Different types of DCCB topologies were investigated in this paper. One of the common limitations of the existing topologies was found to be their inefficient current breaking technique. So, a new and 
efficient current breaking technique along with a new topology was proposed and validated through rigorous simulation. The amount of energy that can be regenerated totally depends on the current that needs to be broken and the system inductances. Hence, highly inductive DC network is going to be a very suitable area for the application of the proposed topology as it will ensure efficient current breaking and will conserve energy. However, it was found that the short time duration of the regenerated current had created high power surge due to high energy density. It might be possible to minimize the power surge by regulating the regenerated current. A high voltage surge was generated as well during breaker turn off process and this surge voltage needs to be limited to keep it within acceptable equipment ratings. In addition, the energy recovery efficiency of the proposed model was found to be $35.4 \%$ which is still very low. So, future scopes are there to extend this study further to resolve the issues such as regulating the regenerated current to make it smoother, keeping the system voltage within acceptable limit during breaker turn off process and to increase the energy recovery efficiency.

\section{ACKNOWLEDGEMENTS}

This work was facilitated by Universiti Teknologi PETRONAS.

\section{REFERENCES}

[1] S. Beheshtaein, R. Cuzner, M. Savaghebi, and J. M. Guerrero, "Review on microgrids protection," IET Gener. Transm. Distrib., vol. 13, no. 6, pp. 743-759, 2019, doi: 10.1049/iet-gtd.2018.5212.

[2] S. Beheshtaein, R. M. Cuzner, M. Forouzesh, M. Savaghebi and J. M. Guerrero, "DC Microgrid Protection: A Comprehensive Review," in IEEE Journal of Emerging and Selected Topics in Power Electronics, 2019, doi: 10.1109/JESTPE.2019.2904588.

[3] D. Kumar, F. Zare and A. Ghosh, "DC microgrid technology: System architectures, AC grid interfaces, grounding schemes, power quality, communication networks, applications, and standardizations aspects," in IEEE Access, vol. 5, pp. 12230-12256, 2017, doi: 10.1109/ACCESS.2017.2705914.

[4] W. Kim, Y. J. Kim, and H. Kim, "Arc voltage and current characteristics in low-voltage direct current," Energies, vol. 11, no. 10, pp. 1-14, 2018, doi: 10.3390/en11102511.

[5] G. P. Adam, T. K. Vrana, R. Li, P. Li, G. Burt, and S. Finney, "Review of technologies for DC grids - power conversion, flow control and protection," IET Power Electron., vol. 12, no. 8, pp. 1851-1867, 2019, doi: ietpel.2018.5719.

[6] J. Ma, M. Zhu, X. Cai and Y. W. Li, "DC substation for DC Grid-Part I: Comparative evaluation of DC substation configurations," in IEEE Transactions on Power Electronics, vol. 34, no. 10, pp. 9719-9731, Oct. 2019, doi: 10.1109/TPEL.2019.2895043.

[7] Y. Wang, et al., "Generalised protection strategy for HB-MMCMTDC systems with RL-FCL under DC faults," IET Gener. Transm. Distrib., vol. 12, no. 5, pp. 1231-1239, 2018, doi: 10.1049/iet-gtd.2016.1943.

[8] N. B. Jemaa, "Short arc duration laws and distributions at low current (<1 A) and voltage (14-42 VDC)," in IEEE Transactions on Components and Packaging Technologies, vol. 24, no. 3, pp. 358-362, Sept. 2001, doi: 10.1109/6144.946480.

[9] B. Ni, W. Xiang, Z. Yuan, X. Chen, and J. Wen, "Operation and transient performance of a four-terminal MMC based DC grid implementing high power mechanical DC circuit breaker," J. Eng., vol. 2019, no. 18, pp. 51675171, 2019, doi: 10.1049/joe.2018.9257.

[10] D. Jovcic, "Series LC DC circuit breaker," High Volt., vol. 4, no. 2, pp. 130-137, 2019, doi: 10.1049/hve.2019.0003.

[11] B. Li, J. He, Y. Li and R. Li, "A Novel solid-state circuit breaker with self-adapt fault current limiting capability for LVDC distribution network," in IEEE Transactions on Power Electronics, vol. 34, no. 4, pp. 3516-3529, Apr. 2019, doi: 10.1109/TPEL.2018.2850441.

[12] Y. Guo, G. Wang, D. Zeng, H. Li and H. Chao, "A thyristor full-bridge-based DC circuit breaker," in IEEE Transactions on Power Electronics, vol. 35, no. 1, pp. 1111-1123, Jan. 2020, doi: 10.1109/TPEL.2019.2915808.

[13] J. Xu, X. Zhao, N. Han, J. Liang and C. Zhao, "A thyristor-based DC fault current limiter with inductor insertingbypassing capability," in IEEE Journal of Emerging and Selected Topics in Power Electronics, vol. 7, no. 3, pp. 1748-1757, Sept. 2019, doi: 10.1109/JESTPE.2019.2914404.

[14] A. Mokhberdoran, A. Carvalho, N. Silva, H. Leite, and A. Carrapatoso, "Design and implementation of fast current releasing DC circuit breaker," Electr. Power Syst. Res., vol. 151, pp. 218-232, 2017, doi: 10.1016/j.epsr.2017.05.032.

[15] A. Shukla and G. D. Demetriades, "A survey on hybrid circuit-breaker topologies," in IEEE Transactions on Power Delivery, vol. 30, no. 2, pp. 627-641, April 2015, doi: 10.1109/TPWRD.2014.2331696.

[16] C. Peng, I. Husain, A. Q. Huang, B. Lequesne and R. Briggs, "A fast mechanical switch for medium-voltage hybrid DC and AC circuit breakers," in IEEE Transactions on Industry Applications, vol. 52, no. 4, pp. 2911-2918, Jul.Aug. 2016, doi: 10.1109/TIA.2016.2539122. 
[17] F. C. Amanze and A. D. Josiah, "Fault analysis in power system using power systems computer aided design," International Journal of Advances in Applied Sciences (IJAAS), vol. 9, no. 3, pp. 171-179, September 2020, doi: 10.11591/ijaas.v9.i3.pp171-179.

[18] A. H. Chang, B. R. Sennett, A. Avestruz, S. B. Leeb and J. L. Kirtley, "Analysis and design of DC system protection using Z-source circuit breaker," in IEEE Transactions on Power Electronics, vol. 31, no. 2, pp. 10361049, Feb. 2016, doi: 10.1109/TPEL.2015.2415775.

[19] G. Li, J. Liang, S. Balasubramaniam, T. Joseph, C. E. Ugalde-Loo and K. F. Jose, "Frontiers of DC circuit breakers in HVDC and MVDC systems," 2017 IEEE Conference on Energy Internet and Energy System Integration (EI2), 2017, pp. 1-6, doi: 10.1109/EI2.2017.8245743

[20] S. M. Sanzad Lumen, R. Kannan and N. Z. Yahaya, "DC circuit breaker: A comprehensive review of solid state topologies," 2020 IEEE International Conference on Power and Energy (PECon), 2020, pp. 1-6, doi: 10.1109/PECon48942.2020.9314300.

[21] K. A. Corzine, "A new-coupled-inductor circuit breaker for DC applications," in IEEE Transactions on Power Electronics, vol. 32, no. 2, pp. 1411-1418, Feb. 2017, doi: 10.1109/TPEL.2016.2540930.

[22] Z. Miao, G. Sabui, A. Moradkhani Roshandeh and Z. J. Shen, "Design and analysis of DC solid-state circuit breakers using SiC JFETs," in IEEE Journal of Emerging and Selected Topics in Power Electronics, vol. 4, no. 3, pp. 863-873, Sept. 2016, doi: 10.1109/JESTPE.2016.2558448.

[23] F. Xu, Y. Lu, X. Xuan, H. Yu, P. Qiu, and D. Jiang, "Self-energy device for HVDC breakers and its control strategy," J. Eng., vol. 2019, no. 16, pp. 2397-2400, 2019, doi: 10.1049/joe.2018.8700.

[24] L. Liu, J. Zhuang, C. Wang, Z. Jiang, J. Wu and B. Chen, "A hybrid DC vacuum circuit breaker for medium voltage: Principle and first measurements," in IEEE Transactions on Power Delivery, vol. 30, no. 5, pp. 2096-2101, Oct. 2015, doi: 10.1109/TPWRD.2014.2384023.

[25] C. Peng, X. Song, A. Q. Huang and I. Husain, "A medium-voltage hybrid DC circuit breaker-Part II: Ultrafast mechanical switch," in IEEE Journal of Emerging and Selected Topics in Power Electronics, vol. 5, no. 1, pp. 289296, March 2017, doi: 10.1109/JESTPE.2016.2609391.

[26] X. Pei, O. Cwikowski, A. C. Smith and M. Barnes, "Design and experimental tests of a superconducting hybrid DC circuit breaker," in IEEE Transactions on Applied Superconductivity, vol. 28, no. 3, pp. 1-5, Apr. 2018, Art no. 5000205, doi: 10.1109/TASC.2018.2793226.

\section{BIOGRAPHIES OF AUTHORS}

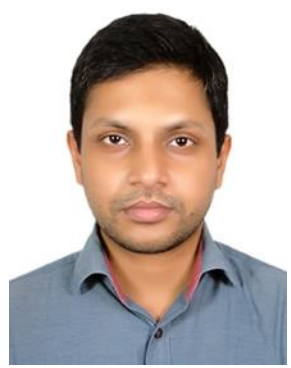

S. M. Sanzad Lumen is a graduate assistant pursuing his M.Sc. degree at Universiti Teknologi Petronas (UTP), Malaysia. He obtained B.Sc. degree in Electrical \& Electronics Engineering from Rajshahi University of Engineering \& Technology (RUET), Bangladesh in 2008. His research interest includes Power System Protection, DC Microgrid, Solar Photovoltaic System, DC Transmission and Distribution System, Smart Grid and Renewable Energy. He is affiliated with IEEE as student member. He has served as an invited reviewer for IEEE Transactions on Circuits and Systems II. Besides, he is an employee of Bangladesh Power Development Board (BPDB) where he had been discharging his duties as Executive Engineer before starting his postgraduate studies. He has long time experience in designing MV/LV distribution system, solar photovoltaic system and was involved in several project feasibility studies, project documentation and policy making tasks in his professional career.

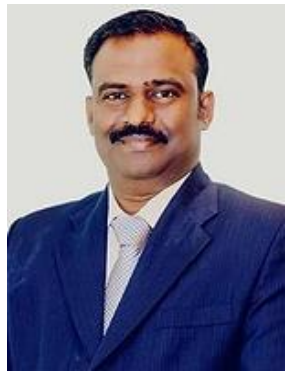

Ramani Kannan is a Senior lecturer in Universiti Teknologi PETRONAS, Malaysia. He received his B.E degree from Bharathiyar University, India. Later, completed his M.E and Ph.D in Power Electronics and Drives from Anna University respectively. He holds more than 95 publications in reputed international and national journals and conferences. He is an active senior member of IEEE, IETE, ISTE and Institute of advance engineering and science. He is the Editorin-Chief for the journal of Asian Scientific Research since 2011 and Regional editor for International Journal of Computer Aided Engineering and technology, Inderscience Publisher, UK from 2015. He is an Associate Editor of IEEE Access since 2018. Dr Ramani has also served as guest editors for Elsevier journal, IGI Global and IJPAM etc. His research interest involves power electronics, inverters, modeling of induction motor and optimization techniques.

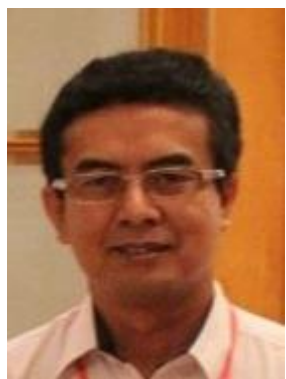

Nor Zaihar Yahaya was born in Lumut, Malaysia. He went to the University of MissouriKansas City, USA to study electronics. He graduated with B.Sc. in Electrical Engineering in 1996. After that he served 5 years in the industry in Malaysia. In 2002, he was awarded M.Sc. in Microelectronics from the University of Newcastle Upon Tyne, UK. Then, in 2011, he received $\mathrm{PhD}$ from the Universiti Teknologi PETRONAS, Malaysia. He is currently an Associate Professor, teaching and doing research in the area of Power Electronics \& Drives. He has published more than 70 papers in proceedings, journals and book chapter with several Patent and Copyright granted. Additionally, he is actively working on projects related to Renewable Energy applications for the government, industry and PETRONAS. 